ต

columns is a largely neglected issue in the field of organisational studies.

Solomos (1999) criticises the definition of institutional racism given by MacPherson and cautions against 'using such terminology... loosely and rhetorically'. The discourse must be given a context within the particular setting being considered, as only then can we begin to understand how the discourse itself determines our conceptions about race or ethnicity.

We do agree with McKenzie \& Bhui that it is important to focus on the needs of patients. Notwithstanding our concern that institutional discrimination may be one factor in the over-representation of Black groups in mental health services, we believe that much more must be done to tackle the problem. The disproportionate admission and detention rates for Black groups, especially (young) Black British men and women, suggests either serious problems with public services (including mental health services) or an epidemic of mental illness in these groups. Whichever it is, whether it is a mixture of factors, it demands urgent attention, with the recognition that this is not solely a health service issue but requires concerted crossgovernment action.

MENTAL HEALTHACTCOMMISSION (2006) Count Me In: The National Mental Health and Ethnicity Census 2005 Service User Survey. MHAC

NKOMO, S. (1992) The emperor has no clothes: rewriting 'race in organizations'. Academy of Management Review, 17, 487-513.

NORFOLK, SUFFOLK AND CAMBRIDGESHIRE STRATEGIC HEALTH AUTHORITY (2003) Independent Inquiry into the Death of David Bennett. NSCSHA.

SAINSBURY CENTRE FOR MENTAL HEALTH (2002) Breaking the Circles of Fear: A Review of the Relationship Between Mental Health Services and African and Caribbean Communities. SCMH.

SOLOMOS, J. (1999) Social research and the Stephen Lawrence Inquiry. Sociological Research Online. http://www.socresonline.org.uk/cgi-bin/ abstract.pl?4/lawrence/solomos.html

Kamlesh Patel Chairman, Mental Health Act Commission, Chris Heginbotham Chief Executive, Mental Health Act Commission

doi: 10.1192/pb.31.10.397a

The central point of Professor Singh's piece (pp. 363-365, this issue) is that neither institutional nor individual-level racism accounts for the high rates of serious mental illness among AfricanCaribbean and African people living in England. Patel \& Heginbotham (pp. 367368 , this issue) claim that all the evidence suggests that Black people and many people from other minority ethnic groups are being admitted to and detained in psychiatric hospitals either unnecessarily or at disproportionate rates'. There is absolutely no evidence for the former and scant evidence for the latter. Rather, as with alcoholism in Scottish and Irish, and coronary artery disease in Asian people living in England, the raised admission rates among Black people in England are a proportionate response to high rates of illness onset. Research shows that it is the circumstances in which Black people live in England that account for the vast bulk of the excess of illness. Attributing the high rates to racism (institutional or otherwise) in the psychiatric services does a disservice to ill Black people and their families who are in immediate need of skilled help. It also prevents a focus on the real culprits, which are discrimination and isolation in society, unemployment, insufficient support for poor families and single mothers, and being brought up in inner cities where crime and drug misuse are rife. Until exposure to these risk factors is diminished, people of African-Caribbean, and to a lesser extent African origin will continue to become ill at rates considerably above those of both the native White population and other minority groups living in England. As Professor McKenzie wrote in the Guardian recently (2 April 2007) when discussing the high rates of serious mental illness in Black British people: 'If we knew that one group in society were 10 times more likely to develop lung cancer, we would focus on them - perhaps with a targeted antismoking strategy. We would not just make lung cancer treatment services more equitable.'

${ }^{*}$ Robin M. Murray Professor of Psychiatry, Institute of Psychiatry, King's College, London SE5 8AF and Visiting Professor, University of the West Indies, email: robin.murray@iop.kcl.ac.uk, Paul Fearon Senior Lecturer, Institute of Psychiatry, King's College London and Consultant sychiatrist, South London and Maudsley NHS FoundationTrust

doi: $10.1192 / p b .31 .10 .398$

\section{Using the media as an educational tool}

Many people from the South-Asian community do not have English as their primary language. First-generation SouthAsians have high rates of illiteracy, and health information may be better communicated by television and radio programmes in their native language. Health information in a variety of languages in written form is becoming more accessible, but is not useful for those who cannot access it because of literacy difficulties.

Recently an opportunity arose to discuss issues related to mental health on a local Asian radio station in Nottingham and an Asian channel on satellite television. I found it a valuable learning experience and was encouraged by the positive feedback from the public. Speaking in the Kashmiri language to a predominantly Pakistani audience allowed participation of members of our communities who are often reluctant or unable to share their views and concerns on mental health matters.

I would encourage my psychiatry colleagues to take any opportunities that may arise to utilise their language skills in the mental health education of the general public using the local, national or even international media.

Masood Aslam Consultant in General Adult Psychiatry, Pennine Care NHS Trust, Royal Oldham Hospital, Oldham OL12JH, email: masood.aslam@ nhs. net

doi: 10.1192/pb.31.10.398a

\section{Psychotherapy competencies in trainees in South Wales}

A survey of psychiatric trainees was conducted in South Wales based on suggested educational experiences / competencies set by the Psychotherapy Specialist Advisory SubCommittee of the Royal College of Psychiatrists' Specialist Training Committee for trainees not undergoing specialist psychotherapy training.

Out of 88 trainees applying for ST2 and ST3 from all five training schemes in South Wales, 40 returned completed questionnaires. None of the surveyed trainees had all the competencies required to apply for their respective ST grade at the time the survey was conducted. Numbers of trainees achieving the suggested educational experiences/competencies were as follows: case presentations in Balint groups, $n=5$; extended psychotherapy case, $n=1$; briefer psychology interventions, $n=2$; paper presentations on psychological treatments, $n=3$; attendance at psychotherapy unit business meeting, $n=3$; patient assessments for psychological treatment with trainer, $n=8$; didactic input for assessment of patients for psychological treatment, $n=11$.

Trainees from resource-poor regions are disadvantaged when applying in open competition with trainees from regions blessed with better infrastructure and training facilities. It seems unfair to expect trainees to demonstrate competencies for which they have not been provided the educational supervision or opportunity to develop. From a trainee's perspective, it would have been better if the list of competencies had been finalised and circulated earlier, giving trainees more time to achieve them. It would also have helped the trainees if competencies could have been drawn up to reflect achievable standards across the entire UK and not just standards achievable in a 
select few well-funded and wellresourced regions.

*Rehan Ahmed Siddiquee Specialist Registrar in General Adult Psychiatry, West Midlands, email: rehon_007@hotmail.com, Arif A. Qadir Senior House Officer in Psychiatry, Cefn Coed Hospital, Swansea

doi: $10.1192 / p b .31 \cdot 10.398 b$

\section{Awareness of psychosexual problems in psychiatric patients among trainees in Pakistan}

Dr Raffi (Psychiatric Bulletin, June 2007,

31, 233-234) has raised some

interesting points about sexual dysfunction among patients of south-east Asian background. This is an issue which psychiatrists working in south-east Asian countries face routinely in their clinical practice.

We recently carried out a survey among psychiatric trainees in a teaching hospital in Peshawar, Pakistan enquiring about their awareness and understanding of psychosexual problems in psychiatric patients. Sixteen doctors (15 males, 1 female; age range 28-42 years) completed the questionnaire and although all were aware of the existence and likely causes of sexual dysfunction in psychiatric patients, only 6 said that they were routinely carrying out assessments of psychosexual functioning. Although most doctors (11 out of 16) felt comfortable about assessing such patients, they thought that patients were very uncomfortable talking about problems of such a sensitive nature. Nearly all doctors (14 out of 16) thought that the patients were unable to openly express themselves about their sexual problems. The most common problems identified by doctors were reduced libido, erectile dysfunction and premature ejaculation. Only 6 doctors thought that patients were getting adequate help for their psychosexual symptoms; the remaining 10 said that patients were just given reassurance.

All 16 doctors felt that there was a need for specific training for the adequate assessment and management of sexual dysfunctions in a manner which was culturally sensitive and acceptable to these patients. The stigma associated with psychiatric problems in general, owing to cultural and religious barriers, was further compounding the whole issue.

It is therefore pertinent that psychiatrists, especially in low- and middleincome countries, spend more time with patients to try to allay their anxieties about their psychosexual problems.

Rameez Zafar Consultant Psychiatrist Lincolnshire Partnership NHS Trust, email: rameez.zafar@|pt.nhs.uk, Khurram Sadiq Senior House Officer in Forensic Psychiatry, Lincolnshire Partnership NHS Trus

doi: $10.1192 / \mathrm{pb} .31 .10 .399$

\section{Crisis resolution \\ and home treatment teams and admissions}

Jethwa et al (Psychiatric Bulletin, May 2007, 31, 170-172) discussed several reasons for the $37.5 \%$ reduction in monthly admission following the formation of the crisis resolution and home treatment service in Leeds. The question remains: which one of these factors has the greatest influence? There is little doubt that screening the patient first by competent crisis resolution staff and the availability of home treatment helps to avoid inappropriate admissions. However, the formation of the service was at the same time as the $35 \%$ reduction of 54 general adult beds from 155 to 101. It is well known that if there are fewer beds the threshold for admission goes up and only the more severely ill and those on sections are admitted.

Unfortunately Jethwa et al did not provide other data which might help to explain the lower admission rates. These include occupancy rates before and after formation of the service, if rates of patients admitted under the Mental Health Act 1983 had increased, if consultants had difficulty in finding a bed or had to put patients on a waiting list for admission, and if alternative in-patient facilities were used (e.g. other respite beds, hostels, private hospitals, etc.). Perhaps the more likely explanation for the $37.5 \%$ reduction in admission rates is that there were 35\% fewer beds for admission and only the most severely ill were admitted.

Seng-Eng Goh Consultant in Old Age Psychiatry Bushey Fields Hospital, Dudley DY1 2LZ, email: Dr Seng-Eng.Goh@dudley.nhs.uk

doi: 10.1192/pb.31.10.399a

Authors' reply: We agree with Dr Goh that the $37.5 \%$ reduction in monthly admissions cannot be directly attributed to the implementation of the crisis resolution and home-based treatment service. Only high-quality randomised controlled trials can make unbiased assertions about the effectiveness of interventions without raising doubts about confounding variables. Such trials have already been conducted using operational definitions of 'crisis' and have demonstrated favourable results (Johnson et al, 2005). Unfortunately these studies often lack external validity. We believe that the strength of our study relates to its naturalistic design, as all patients were included. It is essentially a service evaluation which demonstrates the effectiveness of crisis resolution services in everyday clinical practice.

Dr Goh highlights potential confounding variables and we agree that many of these factors warrant further investigation. We are aware of no significant changes in the factors identified, in particular, the use of independent hospitals is often carefully regulated and their use is minimal given the financial implications. Unfortunately very few services introduce $24 \mathrm{~h}$ crisis resolution services without simultaneously closing in-patient beds. Our study must be considered in the context of recent randomised trials. When taking these into account we believe that crisis resolution and home-based treatment services reduce admission rates, although we accept that other variables may have an effect, and this requires further research.

JOHNSON, S., NOLAN, F., PILLING, S., et al (2005) Randomised controlled trial of acute mental health care by a crisis resolution team: the north Islington crisis study. BMJ, 331, 599-602.

*Krishma Jethwa Specialist Registrar in General Adult Psychiatry, South Hams CMHT, 8 Fore Street, Ivybridge, Devon PL21 9AB, email: dr.k.jethwa@ doctors.org.uk, Nuwan Galappathie Specialist Registrar in Forensic Psychiatry, Langdon Hospital Dawlish, Devon, Paul Hewson Senior Lecturer in Statistics, School of Mathematics and Statistics, University of Plymouth, Devon

doi: 10.1192/pb.31.10.399b 